\title{
Neural stem cell transplantation for the treatment of primary torsion dystonia: A case report
}

\author{
WEN-QING REN ${ }^{1}$, FENG YIN ${ }^{1}$, JIAN-NING ZHANG ${ }^{1}$, WANG-SHENG LU ${ }^{1}$, \\ YING-KUI LIANG ${ }^{2}$, JOSEFIN ADLERBERTH ${ }^{3}$ and ZENG-MIN TIAN ${ }^{1}$ \\ ${ }^{1}$ Institute of Neurosurgery; ${ }^{2}$ PET Center, The PLA Navy General Hospital, Beijing 100048, P.R. China; \\ ${ }^{3}$ Department of Pure and Applied Biochemistry, Lund University, Lund, 22100 Scania, Sweden
}

Received April 7, 2015; Accepted May 5, 2016

DOI: $10.3892 /$ etm.2016.3392

\begin{abstract}
Primary torsion dystonia (PTD) occurs due to a genetic mutation and often advances gradually. Currently, there is no therapy available that is able to inhibit progression. Neural stem cells (NSCs) are being investigated as potential therapies for neurodegenerative diseases, such as stroke and trauma. The present study evaluated the clinical effectiveness of NSC transplantation in an 18-year-old male patient with PTD, to assess the ability of this therapy to inhibit PTD progression. Genetic testing of the patient revealed a mutation in the torsion dystonia-1 (DYT1) gene (907-909 delGAG). NSCs were bilaterally implanted in the globus pallidus of the patient through stereotactic surgery. Prior to surgery, the patient's Burke-Fahn-Marsden dystonia movement score (BFMDMS) was 21 , which progressively decreased after surgery to 18,17 , 15 and 13 at 1, 2, 3 and 4 postoperative years, respectively. BFMDMS was improved by $38.1 \%$ over the 4 postoperative years. Although computed tomography and magnetic resonance imaging examinations showed no significant changes prior to and following surgery, postoperative brain positron emission tomography scans revealed increased glucose metabolism in the transplanted region. The clinical efficacy of NSC transplantation in this patient suggests its potential for the treatment of $D Y T 1$-positive patients with PTD.
\end{abstract}

\section{Introduction}

Dystonia involves the simultaneous contraction of agonist and antagonist muscles, resulting in involuntary sustained and repetitive postures, as well as directional movements (1). The pathogenesis of primary torsion dystonia (PTD) has been correlated with several genetic mutations (2). PTD often

Correspondence to: Dr Zeng-Min Tian, Institute of Neurosurgery, The PLA Navy General Hospital, 6 Fucheng Road, Beijing 100048, P.R. China

E-mail: tianzengmin@vip.sina.com; tianzengminhj@163.com

Key words: primary torsion spasm, torsion dystonia-1, frameless stereotactic surgery, neural stem cells, transplantation causes severe disabilities in patients. Traditional therapies for PTD include oral anti-parkinsonism drugs (3-5), botulinum neurotoxin (6), pallidotomy (7) and deep brain stimulation (DBS) (8). However, these therapies are often ineffective in preventing PTD progression, can induce substantial side effects, and can be cost prohibitive (for example, DBS equipment). Neural stem cell (NSC) therapies have made some clinical progress in the areas of Parkinson's disease, cerebellar atrophy, stroke and other neurological diseases (9-20). The clinical efficacy of this approach has provided hope for its use in inhibiting PTD progression.

The present study explored the effectiveness of NSC transplantation through stereotactic surgical delivery in a patient with PTD, who exhibited partial restoration of neural function during follow-up for 4 years subsequent to surgery. To the best of our knowledge, this is the first report of NSC transplantation used in the treatment of PTD.

\section{Case report}

Patient selection. The patient selected for this study was an 18-year-old male with PTD, who was born through cesarean section on the expected date, did not have a family history of any genetic disease, and had no history of encephalitis, jaundice, brain tumor or trauma. He first exhibited involuntary spasms and torsion of the left lower limb at 5 years of age, without any precipitating factor. The clinical features gradually extended to the entire body from age 5 to 9 years. At 18 years, the patient was unable to write, grip, stand or walk. He had some difficulty in swallowing solid food, but did not have epileptic symptoms. The patient's intelligence was normal. Head computed tomography (CT; Fig. 1a) and magnetic resonance imaging (MRI; Fig. 2a) suggested mild atrophy of the brain. PTD was diagnosed on the basis of the aforementioned data.

Previous therapies had included antispasm treatment (baclofen), sedation (diazepam) and botulinum toxin injection (bilateral lower limbs). These therapies provided little improvement and their side effects were intolerable. In August 2007, the patient underwent DBS, which eased his symptoms to some extent; however, this therapy failed as a result of a serious infection in the chest incision 3 weeks later. After being informed of the details of the study, the patient's 
mother provided written informed consent for the clinical study and surgery. The protocol and patient consent form were approved by the Institutional Review Board of the Navy General Hospital (Beijing, China) and a Performance and Safety Monitoring Board appointed by the National Institutes of Health (no. 2007AA04Z246).

Genetic testing. The patient provided $10 \mathrm{ml}$ peripheral blood, which was collected in an ethylenediamine tetraacetic acid (EDTA) tube and stored at $-20^{\circ} \mathrm{C}$. Whole-blood DNA was extracted by a standard method (21). Exon 5 of the torsion dystonia-1 (DYT1) gene, also known as torsin family 1 member A (TORIA) was amplified by the polymerase chain reaction (PCR) with FastStart Taq DNA Polymerase (Roche Diagnostics, Basel, Switzerland) and forward and reverse primers as follows: DYT1 forward, 5'-CCTGGAATACAA ACACCTA-3' and reverse 5'-GGCTGCCAATCATGACTG TC-3') under the following PCR conditions: 1 cycle at $94^{\circ} \mathrm{C}$ for $5 \mathrm{~min}$, followed by 32 cycles of $94^{\circ} \mathrm{C}$ for $1 \mathrm{~min}, 60^{\circ} \mathrm{C}$ for $1 \mathrm{~min}$ and $72^{\circ} \mathrm{C}$ for $1 \mathrm{~min}$, and a final cycle at $72^{\circ} \mathrm{C}$ for $5 \mathrm{~min}$. The PCR product was sequenced using an ABI 3500xL Sequencer (Guangzhou Golden Mile Medical Testing Center Co., Ltd., Guangzhou, China; http://www.kingmed.com.cn).

Patient evaluation. Neurological function, complications and neuroimaging assessments by MRI (Signa Horizon LX, 1.5T; GE Healthcare Life Sciences, Pittsburgh, PA, USA), and positron emission tomography (PET) were performed prior to and following surgery. A CT scan (Brilliance iCT; Philips Healthcare, Andover, MA, USA) was performed at 3 postoperative days (POD). The PET scan was performed with ${ }^{18} \mathrm{~F}$-fluorodeoxyglucose $\left({ }^{18} \mathrm{~F}-\mathrm{FDG}\right.$; radiochemical purity $>95 \%$; Atomic High-Tech Co., Ltd., Beijing, China) on a GE Discovery ST 16 PET/CT scanner (GE Healthcare Life Sciences).

The patient's motor function was assessed by comparing his pre- and post-operative Burke-Fahn-Marsden dystonia movement scores (BFMDMSs) (22). The improvement rate at 4 years after surgery was calculated as follows: Improvement rate $(\%)=($ preoperative score - postoperative score $) /$ preoperative score $\mathrm{x} 100$. The follow-up period began in July 2008 and ended in October 2012.

Donor tissue and NSC cultures. Donor tissue was obtained from the brain of a 5- to 11-week-old fetus, which was spontaneously aborted from a healthy pregnant woman. The woman had no family history of genetic disease or intrauterine infection. NSC cultures for transplantation tested negative for human herpesvirus, cytomegalovirus, fungi and bacteria. Donor tissue was obtained from the fetal basal ganglia under sterile conditions. The tissue was cut into small pieces (1-2 mm in diameter), digested for $30 \mathrm{~min}$ at $37^{\circ} \mathrm{C}$ with pancreatin $(1 \%)$ and digested for $10 \mathrm{~min}$ at $37^{\circ} \mathrm{C}$ with DNase $(40 \mu \mathrm{g} / \mathrm{ml})$. The tissue was separated into a single-cell suspension with a Pasteur pipette. Cell activity was measured by Trypan blue staining.

Cells $\left(1 \times 10^{5}\right.$ cells $\left./ \mathrm{ml}\right)$ were inoculated in amplifying culture liquid with $\beta$-fibroblast growth factor ( $\beta$-FGF; 20 ng/ml; Gibco; Thermo Fisher Scientific, Inc., Waltham, MA, USA), epidermal growth factor (EGF; $20 \mathrm{ng} / \mathrm{ml}$; Gibco) and B27 serum factor (neural nutritional additive) without blood serum. Cells were cultured in a humidified incubator at $37^{\circ} \mathrm{C}$ and $5 \% \mathrm{CO}_{2}$. Culture medium was changed once every 3.5 days. When NSCs grew into a spheroid shape (Fig. 3a), they were subcultured once at $5-10 \times 10^{4} / \mathrm{ml}$ and then incubated for 7-14 days. After 15 days, spheroidal cell cultures of viable cells were retrieved and adjusted to $4 \times 10^{4}$ cells $/ \mu 1$ in suspension. Cells were incubated for $5 \mathrm{~min}$ at room temperature prior to transplantation. The detailed method for preparing NSCs has been described previously $(9,10,13,21,23)$.

Transplantation method. The patient was anesthetized with intravenous midazolam $(0.15 \mathrm{mg} / \mathrm{kg})$ and propofol $(2.0 \mathrm{mg} / \mathrm{kg})$. Cultured NSCs were transplanted into the bilateral globus pallidus via a frameless stereotactic surgical procedure (Fig. 3b) (9). Feng et al found that local dexamethasone injection reduced the immune rejection and increased the survival of grafted cells, while preventing side effects from long-term immunosuppression (24). Thus, dexamethasone $(0.5-1.0 \mathrm{mg} / 0.2 \mathrm{ml})$ was injected into the target site prior to the implantation of NSCs. A total of $1 \times 10^{7}$ NSCs in $0.25 \mathrm{ml}$ were deposited unilaterally into the globus pallidus. Following surgery, the patient was admitted to the neurosurgical intensive care unit for overnight observation and was transferred to a conventional ward the next morning. Intravenous ceftriaxone sodium ( $2 \mathrm{~g} /$ day $)$ and dexamethasone (10 mg/day) were administered for 3 POD.

Genetic analysis, imaging observations and follow-up. Genetic analysis identified a mutation (907-909 delGAG) in the fifth exon of DYT1 (TORIA) in the patient (Fig. 3c). He exhibited good tolerance of the neurosurgical procedure and was discharged at 4 POD. There were no serious adverse events associated with cell implantation or the surgical procedure. The CT scan at 3 POD revealed no hemorrhage or edema (Fig. 2e). By 1 month after surgery, the PTD symptoms of the patient began to improve. The BFMDMS progressively increased, from 21 prior to surgery to $18,17,15$ and 13 at 1,2 , 3 and 4 years after surgery, respectively, with $38.1 \%$ improvement by 4 years after surgery (Table I).

The CT (Fig. 1b-e) and MRI (Fig. 2b-d) scans showed no significant changes over the 4 -year follow-up period. ${ }^{18} \mathrm{~F}$-FDG PET scans were obtained 1 day before surgery (Fig. 1f) and 1, 2, 3 and 4 years after surgery (Fig. 1g-j). ${ }^{18}$ F-FDG uptake values in the lentiform nucleus and thalamus of the bilateral implant sites were increased after surgery compared with those in the same sites before surgery. This result suggests that glucose metabolism was slightly increased year by year since the transplantation.

\section{Discussion}

As one of the most common and serious forms of hereditary PTD (2), DYT1 is characterized by childhood onset of progressive dystonia, which typically begins as segmental (mostly arm or leg) dystonia and subsequently generalizes (25). The pathology mainly manifests as degeneration of small nerve cells in the caudate nucleus and putamen of the basal ganglia, degeneration of the globus pallidus, and absence of cells in the cerebellar dentate nucleus (26). In the present study, the 
Table I. Follow-up results.

\begin{tabular}{lll}
\hline Time point & BFMDMS Changes in symptoms
\end{tabular}

Preoperative

1 year after treatment

2 years after treatment

3 years after treatment

4 years after treatment
The patient manifested involuntary sustained muscle contractions causing twisting, repetitive movements or abnormal postures affecting the whole body. The patient was unable to write, grip, stand, or walk. He also had some difficulty in swallowing solid food.

The patient was able to write and grasp objects actively with bilateral hands. Muscle tension of the left upper and bilateral lower limbs decreased. Muscle spasm lessened. The left ankle showed active movement. Limb pain was relieved.

Bilateral upper limb activity improved, especially the right hand. The crossing of bilateral lower limbs was less obvious than before. Limb pain was relieved even more.

Significant improvement in activities of the upper limbs and improved crossing of the lower limbs bilaterally were observed. The reduction of limb pain was more substantial and the frequency of pain also declined.

Muscle tension of the left limb clearly declined. The patient was able to grasp objects with his right hand and had no difficulty in swallowing solid food.

BFMDMS, Burke-Fahn-Marsden dystonia movement score.
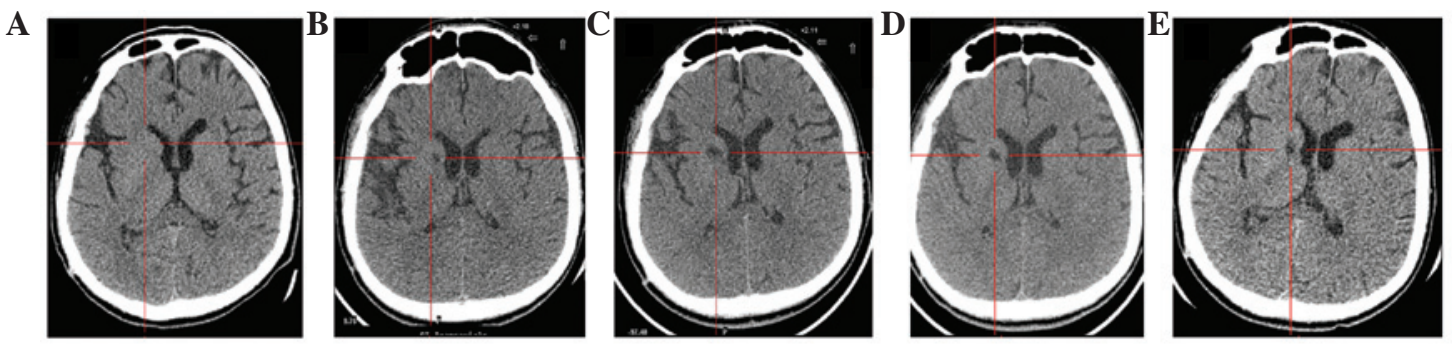

F
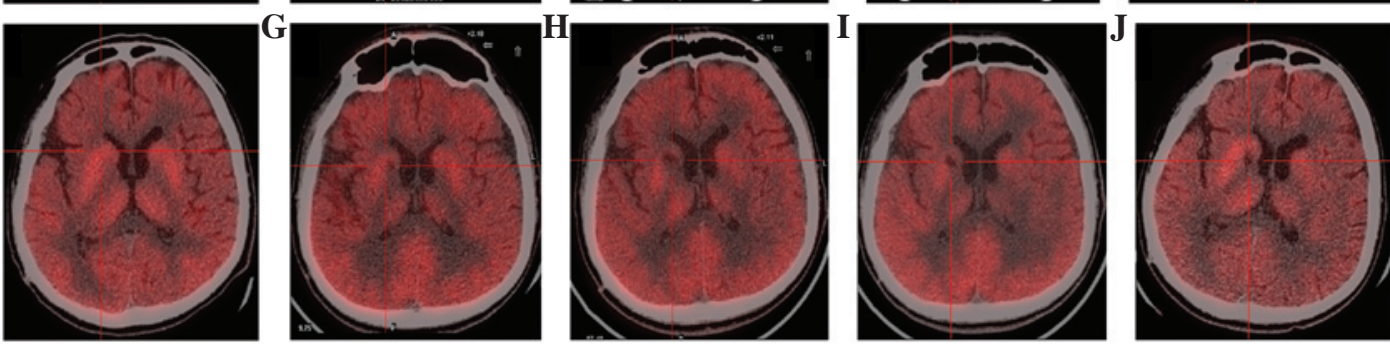

Figure 1. Computed tomography (CT) and positon emission tomography (PET) scans. (A) Preoperative CT showing atrophy of the brain. (B-E) CT showed no significant changes compared with the preoperative CT at $1,2,3$, and 4 years postoperatively, respectively. (F) Preoperative ${ }^{18} \mathrm{~F}-$ fluorodeoxyglucose (FDG) PET scan shows that uptake of FDG in the entire brain cortex was diffusely decreased and uptake of FDG of the nucleus was relatively higher than that of other areas. The standardized uptake value (SUV) average/maximum of the lentiform nucleus and thalamus are $4.3 / 5.8$ and $3.3 / 4.5$, respectively, at 1 day preoperatively. (G-J) ${ }^{18}$ F-FDG PET scans 1, 2, 3, and 4 years, respectively, after neural stem cell transplantation treatment show an increase in the uptake of ${ }^{18} \mathrm{~F}-\mathrm{FDG}$ in the lentiform nucleus and thalamus of the implant sites bilaterally (red cross) compared with the same sites before implantation. The SUV average/maximum of the lentiform nucleus and thalamus are 5.0/6.2 and 4.0/4.8,5.5/6.4 and 4.4/5.0,5.8/6.7 and 4.6/5.2, and 6.0/6.8 and 4.8/5.2 at 1,2,3, and 4 years postoperatively, respectively. This result suggests that glucose metabolism was slightly higher after the transplantation than before. The red cross indicates the right implant site. The SUV is a semi-quantitative indicator for measuring the uptake value of ${ }^{18} \mathrm{~F}$-FDG tracer in tissue.

patient's clinical manifestations were consistent with the DYT1 phenotype, and the genetic test results confirmed that he was DYT1-positive. Brain CT and MRI examinations showed brain atrophy. A brain PET scan showed that glucose metabolism in the cerebral cortex was diffusely decreased. Together, these findings support the aforementioned pathological degeneration pattern.

Over the past 20 years, extensive information has been uncovered about the phenotype of dystonia-related mutations.
In particular, advances in functional neuroimaging have allowed researchers to determine roles for regions of the brain other than the basal ganglia. Lehéricy et al cited the importance of the thalamo-cortical and cerebello-thalamo-cortical circuits in patients with the DYT1 mutation (27). Carbon et al found that individuals with the DYT1 or DYT6 genotype displayed functional and microstructural abnormalities in the cortico-striatal-pallido-thalamo-cortical and cerebellar-thalamo-cortical circuits $(28,29)$, as well as alterations 

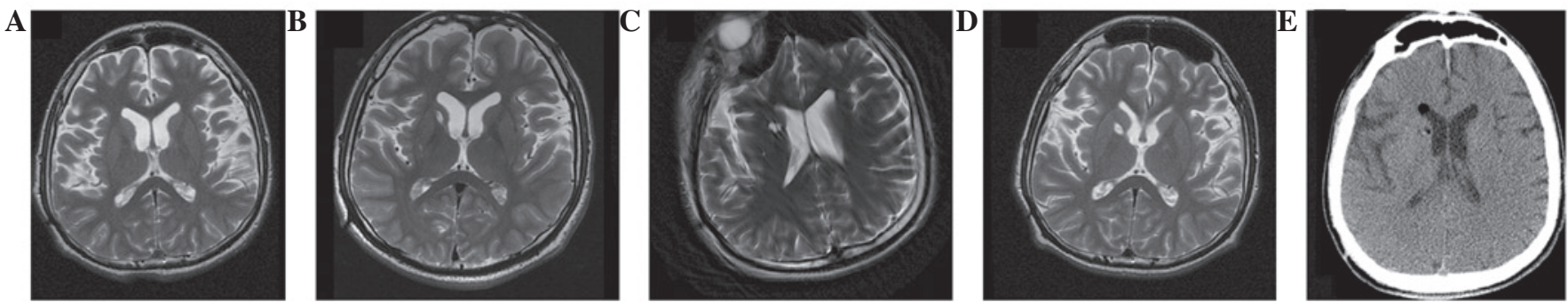

Figure 2. T2-weighted magnetic resonance imaging (MRI). (A) Preoperative MRI showing atrophy of the brain. (B-D) At 1,3 and 4 years postoperatively, MRI showed no significant changes compared with the preoperative MRI. (E) At 3 days postoperatively, computed tomography showed no hemorrhage or edema.
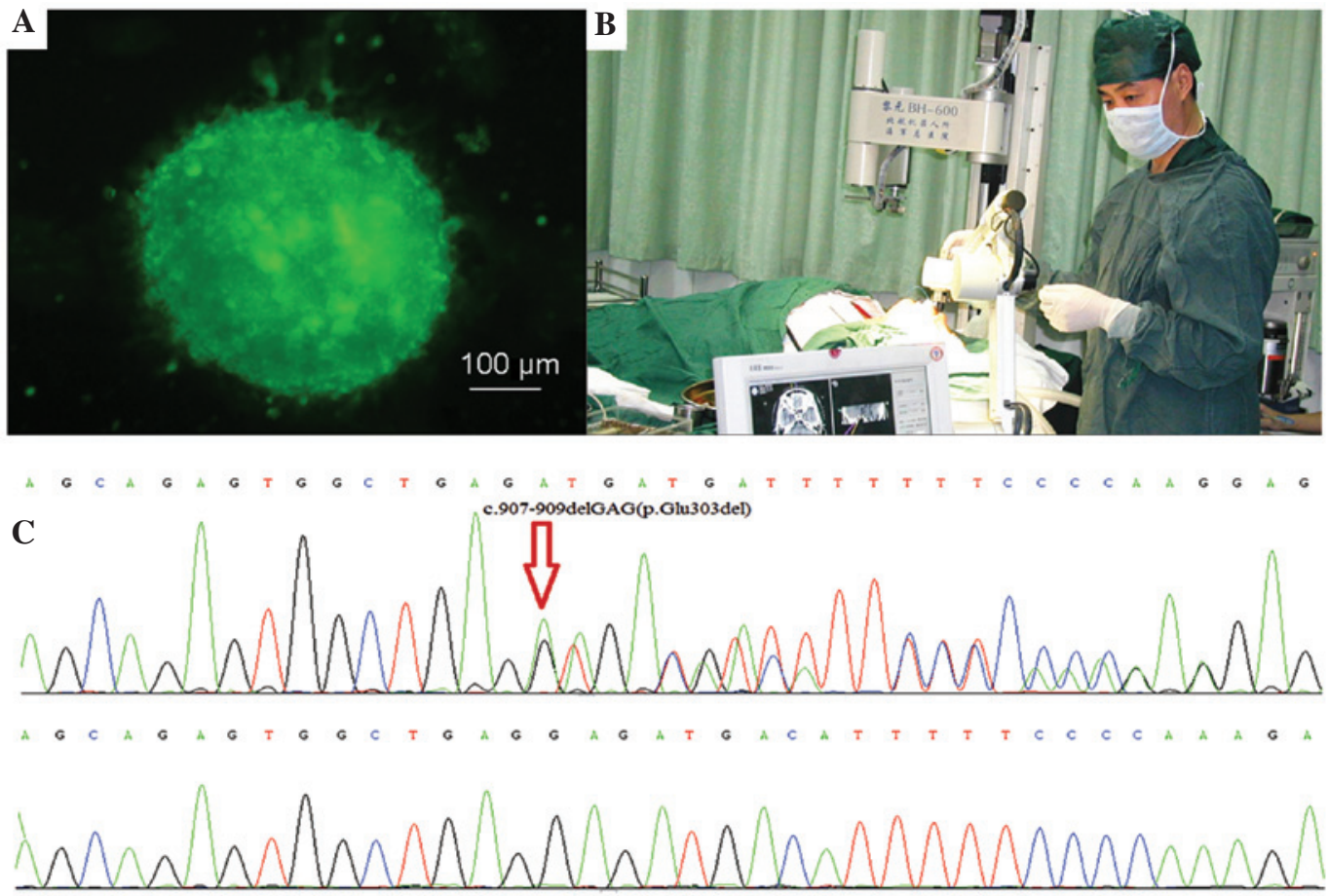

Figure 3. (A) Immunofluorescence features of neural stem cell spheres (nestin stained; magnification, x100). (B) Frameless stereotactic surgery. The patient is at the left of the image and the frameless stereotactic equipment is at the right. (C) The torsion dystonia-1 (DYT1) gene, also known as torsin family 1 member A (TORIA) of the patient with primary torsion dystonia. The fifth exon of the patient's DYT1 gene had a mutation (907-909 del GAG, indicated by the red arrow), and thus the patient was DYT1-positive.

in the pre-supplementary motor area, parietal association area, cerebellum, brainstem and ventral thalamus. The authors proposed an association between the metabolic abnormalities in DYT1 and DYT6 carriers and the connectivity of motor pathways. Trost et al identified DYT1-like metabolic topographical changes in patients with dystonia mutations other than DYT1 (30).

Traditional therapy in PTD includes various drugs, intracerebral nucleus lesions and DBS (3-6,8). Although DBS is favorable to some extent, it is unable to inhibit PTD progression. Recent progress in NSC research has enabled the use of NSC transplantation for PTD treatment. Under certain conditions, NSCs can proliferate, migrate and differentiate into location-specific nerve cells to replace locally damaged cells (31-33). Through these processes, NSCs repair abnormal neural pathways, secrete neurotrophic factors and protect damaged neurons. Thus, NSC transplantation may be able to replenish cells lost due to aging, injury or disease (23,34-36). As NSCs have low immunogenicity (37-39), immunological rejection following transplantation is very mild, providing advantageous conditions for NSC survival. NSC transplantation has been used to treat adults with Parkinson's disease $(9,10,17,20)$, cerebellar atrophy (11) and stroke sequelae $(12-16,18,19)$. The utility of NSCs in these conditions provides the rationale for their use in the treatment of PTD. Researchers mobilized endogenous NSCs from the subventricular zone to replace dopaminergic cells in the substantia nigra, which restored striatal dopamine levels and improved motor symptoms in patients with Parkinson's disease (40).

To the best of our knowledge, this is the first study to use NSC transplantation for the treatment of a patient with DYT1-positive PTD. The patient exhibited deterioration of the brain tissue, as evidenced by brain atrophy on preoperative CT and MRI scans and by a decline in cerebral glucose metabolism on PET scans. Over a 4-year follow-up period, the patient showed no complications as a result of NSC transplantation. He exhibited a continuous decline in BFMDMS, which improved by $38.1 \%$ within 4 years of the procedure. 
The patient's condition began to improve within 1 month and stabilized 6 months after NSC treatment. The glucose uptake increased at the transplantation sites, indicating that the NSCs possibly played roles in the replacement of cells and the repair of neural pathways. Yamada et al indicated that inflammation caused by exogenous tissues may increase ${ }^{18} \mathrm{~F}-\mathrm{FDG}$ uptake (41). However, NSCs with low immunogenicity (37) may cause little inflammation. Thus, the increased ${ }^{18} \mathrm{~F}-\mathrm{FDG}$ uptake may be of little concern in terms of the inflammation caused by the transplanted NSCs.

Based on the pathogenesis of PTD, gene therapy (for example, gene silencing and gene replacement therapy) has been attempted in the past. Suppressing mutant torsin A expression with RNA interference was shown to restore the function of wild-type torsin A in a neural model of DYT1-positive PTD (42).

In the present study, NSC transplantation was accomplished using a frameless stereotactic surgical technique. Stereotactic surgery is a well-established and reliable technology that has been widely used in the neurosurgery clinic for many years (43). The use of stereotactic surgery assured that the positioning was accurate with minimal trauma. The NSCs were transplanted directly into the vicinity of the basal ganglia. The patient did not exhibit hemorrhaging after the NSC treatment.

NSC transplantation in PTD patients is currently in the early clinical exploration phase, and several problems remain to be solved before it can become a standard clinical therapy. First, NSC tumorigenicity continues to be a major concern, and several studies have analyzed the possibility of tumor generation (44-47). The patient in the present study did not develop any nervous system tumors during the 4-year follow-up, but the evaluation of the safety of NSC therapy requires a longer observation time. Secondly, the immunological rejection of NSCs is a relevant concern. The majority of researchers consider that immunological rejection rarely occurs due to the integrity of the blood-brain barrier and the mild immunogenicity of NSCs $(13,33,34,38,47)$. The patient in the current study did not receive long-term immunosuppression therapy and did not develop immunological rejection after NSC transplantation.

NSC transplantation of a DYT1-positive PTD patient showed some clinical efficacy over a 4-year follow-up period. Nevertheless, it is necessary to assess the therapy in more patients and follow them up for a longer time, to confirm the results and determine the mechanism of NSC differentiation.

\section{Acknowledgements}

This study was supported by a grant from the National Natural Science Foundation of China (No. 81172383).

\section{References}

1. Fahn S: Concept and classification of dystonia. Adv Neurol 50 $1-8,1988$

2. Spatola $\mathrm{M}$ and Wider C: Overview of primary monogenic dystonia. Parkinsonism Relat Disord 18 (Suppl 1): S158-S161, 2012.

3. Kenney C and Jankovic J: Tetrabenazine in the treatment of hyperkinetic movement disorders. Expert Rev Neurother 6: 7-17, 2006.
4. Burke RE, Fahn S and Marsden CD: Torsion dystonia: A double-blind, prospective trial of high-dosage trihexyphenidyl. Neurology 36: 160-164, 1986.

5. Woon K, Tsegaye M and Vloeberghs MH: The role of intrathecal baclofen in the management of primary and secondary dystonia in children. Br J Neurosurg 21: 355-358, 2007.

6. Simpson DM, Blitzer A, Brashear A, Comella C, Dubinsky R, Hallett M, Jankovic J, Karp B, Ludlow CL, Miyasaki JM, et al; Therapeutics and Technology Assessment Subcommittee of the American Academy of Neurology: Assessment: Botulinum neurotoxin for the treatment of movement disorders (an evidence-based review): Report of the Therapeutics and Technology Assessment Subcommittee of the American Academy of Neurology. Neurology 70: 1699-1706, 2008.

7. Lozano AM, Kumar R, Gross RE, Giladi N, Hutchison WD, Dostrovsky JO and Lang AE: Globus pallidus internus pallidotomy for generalized dystonia. Mov Disord 12: 865-870, 1997.

8. Vidailhet M, Vercueil L, Houeto JL, Krystkowiak P, Lagrange C, Yelnik J, Bardinet E, Benabid AL, Navarro S, Dormont D, et al: Bilateral, pallidal, deep-brain stimulation in primary generalised dystonia: A prospective 3 year follow-up study. Lancet Neurol 6: 223-229, 2007.

9. Tian ZM, Liu S, Li SY, Zhao QJ, Yin F, Hao QX and Zhou Y: Clinical transplantation of human neural stem cells in treatment of Parkinson disease. Di-Er Junyi Daxue Xuebao 24: 957-959, 2003 (In Chinese).

10. Yin F, Tian ZM, Liu S, Zhao QJ, Wang RM, Shen L, Wieman J and Yan Y: Transplantation of human retinal pigment epithelium cells in the treatment for Parkinson disease. CNS Neurosci Ther 18: 1012-1020, 2012.

11. Tian ZM, Li ZC, Yin F, Li SY and Liu S: Clinical transplantation of human neural stem cells in treatment of cerebellar atrophy. Di-Er Junyi Daxue Xuebao 25: 933-935, 2004 (In Chinese).

12. Lu WS, Tian ZM, Zhao QJ, Liu S, Li ZC, Chen T and Guo XR: Clinical transplantation of human neural stem cells in treatment of stroke sequelae: Report of 16 cases. Zhonghua Shen Jing Wai Ke Ji Bing Yan Jiu Za Zhi 7: 502-504, 2008 (In Chinese).

13. Andres RH, Choi R, Steinberg GK and Guzman R: Potential of adult neural stem cells in stroke therapy. Regen Med 3: 893-905, 2008.

14. Bacigaluppi M, Pluchino S, Martino G, Kilic E and Hermann DM: Neural stem/precursor cells for the treatment of ischemic stroke. J Neurol Sci 265: 73-77, 2008.

15. Kondziolka D, Steinberg GK, Wechsler L, Meltzer CC, Elder E, Gebel J, Decesare S, Jovin T, Zafonte R, Lebowitz J, et al: Neurotransplantation for patients with subcortical motor stroke: A phase 2 randomized trial. J Neurosurg 103: 38-45, 2005.

16. Kondziolka D, Wechsler L, Goldstein S, Meltzer C, Thulborn KR, Gebel J, Jannetta P, DeCesare S, Elder EM, McGrogan M, et al: Transplantation of cultured human neuronal cells for patients with stroke. Neurology 55: 565-569, 2000.

17. Nakao N, Kakishita K, Uematsu Y, Yoshimasu T, Bessho T, Nakai K, Naito Y and Itakura T: Enhancement of the response to levodopa therapy after intrastriatal transplantation of autologous sympathetic neurons in patients with Parkinson disease. J Neurosurg 95: 275-284, 2001.

18. Rabinovich SS, Seledtsov VI, Banul NV, Poveshchenko OV, Senyukov VV, Astrakov SV, Samarin DM and Taraban VY: Cell therapy of brain stroke. Bull Exp Biol Med 139: 126-128, 2005.

19. Savitz SI, Dinsmore JH, Wechsler LR, Rosenbaum DM and Caplan LR: Cell therapy for stroke. NeuroRx 1: 406-414, 2004.

20. Suchowersky O: Transplantation therapy for Parkinson disease: The good, the bad and the enigmatic. Nat Clin Pract Neurol 4: 465, 2008.

21. Al Hashem G, Al Sweih N, Jamal W and Rotimi VO: Sequence analysis of bla (CTX-M) genes carried by clinically significant Escherichia coli isolates in Kuwait hospitals. Med Princ Pract 20: 213-219, 2011.

22. Burk RE, Fahn S, Marsden CD, Bressman SB, Moskowitz C and Friedman J. Validity and reliability of a rating scale for the primary torsion dystonias. Neurology 35: 73-77, 1985.

23. Tian ZM, Yin F, Wang YQ, Liu S and Zhou Y: Transplantation of mesencephalon progenitor cells in treatment of Parkinsonian rats. Di-Er Junyi Daxue Xuebao 24: 954-956, 2003 (In Chinese).

24. Yin F, Zengmin T, Shuang L, Quanjun Z, Yaming W and Qiuxing H: Local effects of dexamethasone on immune reaction in neural transplantation. Transpl Immunol 18: 126-129, 2007.

25. Ozelius LJ, Hewett JW, Page CE, Bressman SB, Kramer PL, Shalish C, de Leon D, Brin MF, Raymond D, Corey DP, Fahn S, Risch NJ, Buckler AJ, Gusella JF and Breakefield XO: The early-onset torsion dystonia gene (DYT1) encodes an ATP-binding protein. Nat Genet 17: 40-48, 1997. 
26. Standaert DG. Update on the pathology of dystonia. Neurobiol Dis 42: 148-151, 2011

27. Lehéricy S, Tijssen MA, Vidailhet M, Kaji R and Meunier S: The anatomical basis of dystonia: Current view using neuroimaging. Mov Disord 28: 944-957, 2013.

28. Carbon M, Argyelan M and Eidelberg D: Functional imaging in hereditary dystonia. Eur J Neurol 17 (Suppl 1): S58-S64, 2010.

29. Carbon $M$ and Eidelberg D: Abnormal structure-function relationships in hereditary dystonia. Neuroscience 164: 220-229, 2009.

30. Trost M, Carbon M, Edwards C, Ma Y, Raymond D, Mentis MJ, Moeller JR, Bressman SB and Eidelberg D: Primary dystonia: Is abnormal functional brain architecture linked to genotype? Ann Neurol 52: 853-856, 2002.

31. Riess P, Zhang C, Saatman KE, Laurer HL, Longhi LG Raghupathi R, Lenzlinger PM, Lifshitz J, Boockvar J, Neugebauer E, et al: Transplanted neural stem cells survive, differentiate and improve neurological motor function after experimental traumatic brain injury. Neurosurgery 51: 1043-1052; discussion 1052-1044, 2002.

32. Imitola J, Raddassi K, Park KI, Mueller FJ, Nieto M, Teng YD, Frenkel D, Li J, Sidman RL, Walsh CA, et al: Directed migration of neural stem cells to sites of CNS injury by the stromal cell-derived factor 1alpha/CXC chemokine receptor 4 pathway. Proc Natl Acad Sci USA 101: 18117-18122, 2004.

33. Wennersten A, Meier X, Holmin S, Wahlberg L and Mathiesen T: Proliferation, migration and differentiation of human neural stem/progenitor cells after transplantation into a rat model of traumatic brain injury. J Neurosurg 100: 88-96, 2004.

34. Isacson O: The production and use of cells as therapeutic agents in neurodegenerative diseases. Lancet Neurol 2: 417-424, 2003.

35. Lindvall O, Kokaia Z and Martinez-Serrano A: Stem cell therapy for human neurodegenerative disorders-how to make it work. Nat Med 10 (Suppl): S42-S50, 2004.

36. Martino G and Pluchino S: The therapeutic potential of neural stem cells. Nat Rev Neurosci 7: 395-406, 2006.
37. Ubiali F, Nava S, Nessi V, Frigerio S, Parati E, Bernasconi P, Mantegazza R and Baggi F: Allorecognition of human neural stem cells by peripheral blood lymphocytes despite low expression of MHC molecules: Role of TGF-beta in modulating proliferation. Int Immunol 19: 1063-1074, 2007.

38. Barker CF and Billingham RE: Immunologically privileged sites. Adv Immunol 25: 1-54, 1977.

39. Pachter JS, de Vries HE and Fabry Z: The blood-brain barrier and its role in immune privilege in the central nervous system. J Neuropathol Exp Neurol 62: 593-604, 2003.

40. van den Berge SA, van Strien ME and Hol EM: Resident adult neural stem cells in Parkinson's disease - the brain's own repair system? Eur J Pharmacol 719: 117-127, 2013.

41. Yamada S, Kubota K, Kubota R, Ido T and Tamahashi N High accumulation of fluorine-18-fluorodeoxyglucose in turpentine-induced inflammatory tissue. J Nucl Med 36: 1301-1306, 1995.

42. Gonzalez-Alegre P, Bode N, Davidson BL and Paulson HL: Silencing primary dystonia: Lentiviral-mediated RNA interference therapy for DYT1 dystonia. J Neurosci 25: 10502-10509, 2005.

43. Tian ZM, Lu WS, Zhao QJ, Yu X, Xu YG, Wang R and Qi SB Clinical analysis of 1434 cases of frameless stereotactic operation. Zhonghua Wai Ke Za Zhi 45: 702-704, 2007 (In Chinese).

44. Walton NM, Snyder GE, Park D, Kobeissy F, Scheffler B and Steindler DA: Gliotypic neural stem cells transiently adopt tumorigenic properties during normal differentiation. Stem Cells 27: 280-289, 2009.

45. Germano I, Swiss V and Casaccia P: Primary brain tumors, neural stem cell and brain tumor cancer cells: Where is the link? Neuropharmacology 58: 903-910, 2010.

46. Fan X, Matsui W, Khaki L, Stearns D, Chun J, Li YM and Eberhart CG: Notch pathway inhibition depletes stem-like cells and blocks engraftment in embryonal brain tumors. Cancer Res 66: 7445-7452, 2006.

47. Abbott NJ, Ronnback L and Hansson E: Astrocyte-endothelial interactions at the blood-brain barrier. Nat Rev Neurosci 7: 41-53, 2006. 